\title{
ANALISIS FREKUENSI DAN BENTUK LETUPAN GUNUNG LUMPUR BLEDUK KUWU
}

\author{
Fita Widiyatun \\ Program Studi Teknik Informatika, Universitas Indraprasta PGRI Jakarta \\ Email: Fita.wdy@gmail.com
}

\begin{abstract}
Abstrak
Bleduk Kuwu merupakan satu dari sekian banyak gunung lumpur di Indonesia yang masih aktif dari jaman dahulu sampai dengan sekarang. Letak Bleduk Kuwu berada di Purwodadi, Grobogan, Jawa tengah. Bleduk Kuwu merupakan objek wisata yang mempunyai letupan sekitar 7 - 15 kali setiap menit. Tujuan dari penelitian ini adalah untuk mengetahui macammacam bentuk letusan yang terjadi di Bleduk Kuwu, besar diameter letupan, serta besar frekuensinya. Pengambilan data dilakukan pada tanggal 30 September 2013, selama 47 menit 27 detik. Alat yang digunakan dalam pengambilan data yaitu tiga buah seismometer TDV-23S feedback short period tiga komponen dan sebuah kamera perekam. Hasil analisis video diperoleh empat macam tipe letusan yang terjadi di Bledug Kuwu. Tipe letupan tersebut adalah letupan kuat, letupan beruntun, letupan ganda, dan letusan biasa. Masingmasing letupan mempunyai diameter yang bervariasi. Ukuran diameter terbesar adalah $(3,1$ $\pm 0,1) \mathrm{m}$ dan diameter letusan yang sering terjadi yaitu $(1,0-2,0) \mathrm{m}$. Analisis sinyal seismik, diperoleh frekuensi letupan yaitu $(1,6-4,2) \mathrm{Hz}$ dengan frekuensi dominan 2,0 Hz.
\end{abstract}

Kata Kunci : Bleduk Kuwu, gunung lumpur, macam-macam letupan, analisis frekuensi.

\begin{abstract}
Bleduk Kuwu is one of the many mud volcanoes in Indonesia are still active from the past to the present. Location of Kuwu Bleduk in Purwodadi, Grobogan, Central Java. Bleduk Kuwu is a tourist attraction that has eruption around 7-15 times per minute. The purpose of this research was to determine the various forms of the eruption that occurred in Bleduk Kuwu, large of diameter eruptions, and frequency. Data is collected on September 30, 2013, during 47 minutes and 27 seconds. The tools used in data collection are three seismometers TDV23 s short feedback period of three components and a camcorder. The results of video analysis, there are four types of eruptions that occurred in Bledug Kuwu. The eruption mode is a powerful eruption, row eruption, double eruption, and regular eruption. Each of the eruption has varying diameters. Size of the largest eruption diameter is $(3.1 \pm 0.1) m$ and the frequent diameter eruptions around $(1.0-2.0) \mathrm{m}$. Analysis of seismic signals, obtained an eruption frequency is (1.6 to 4.2) $\mathrm{Hz}$ with the dominant frequency of $2.0 \mathrm{~Hz}$.
\end{abstract}

Key Word: Bleduk Kuwu, mud volcano, type of eruptions, frequency analysis.

\section{Pendahuluan}

Terdapat beberapa lokasi gunung lumpur di Pulau Jawa. Menurut Istadi, dkk. (2009) Di wilayah Jawa Tengah, Jawa Timur, sampai dengan Madura terdapat sekitar 15 tempat yang terindikasi gunung lumpur. Salah satu gunung lumpur tersebut adalah Bleduk Kuwu.

Bleduk Kuwu merupakan salah satu gunung lumpur yang sangat istimewa. Hal tersebut karena selain gunung lumpur ini sudah aktif sejak lama, Bleduk Kuwu juga merupakan objek wisata andalan di daerah Purwodadi, Grobogan, Jawa Tengah. Hal istimewa lainnya adalah lokasi Bleduk Kuwu yang strategis dan mudah untuk dijangkau, hal itu karena Bleduk Kuwu berada dipinggir jalan (Gambar 1b). Penampakan letupan Bleduk Kuwu seperti pada Gambar 2. Dimensi letupan gunung lumpur Bleduk Kuwu bervariasi, mulai dari ukuran kecil hingga besar. Intensitas letupan Bleduk Kuwu juga tergolong sering, terjadi sekitar 7-15 kali letupan setiap menitnya. Setiap terjadi letupan selalu membawa gas berwarna putih dan 
mengandung garam di dalam material yang dikeluarkan. Warga penduduk setempat biasanya memanfaatkan garam tersebut untuk diolah menjadi garam dapur.

Beberapa penelitian yang pernah dilakukan di Bleduk Kuwu antara lain oleh Sugianto (2014) yaitu melakukan monitoring getaran seismik untuk mempelajari dinamika internal erupsi lumpur dari kedalaman tertentu hingga ke permukaan. Putranti (2015) melakukan pemodelan kecepatan medium bawah permukaan dengan menggunakan metode spatial autocorrelation (SPAC). Gela (2015) melakukan pemodelan bawah permukaan untuk mengetahui bentuk dan kedalaman bedrock di bawah permukaan gunung lumpur Bleduk Kuwu. Rugayya (2015) melakukan karakterisasi sinyal seismik berdasarkan rekaman seismometer dan video secara kuantitatif. Fauzi (2015) melakukan penelitian dengan tujuan untuk mengetahui parameter dan struktur bawah permukaan gunung lumpur Bleduk Kuwu.

Sering terjadinya letupan di Bleduk Kuwu dengan ukuran dan bentuk yang bervariasi, membuat peneliti ingin melakukan kajian lebih mendalam tentang macam-macam bentuk letupan Bleduk Kuwu, melakukan klasifikasi atau pengelompokan terhadap bentuk letupan, mencari diameter terbesar dan kisaran besar diameter yang sering terjadi. Selain itu, peneliti juga ingin mencari besar frekuensi dari letupan-letupan tersebut. Manfaat dari penelitian ini diharapkan dengan diketahuinya macam-macam bentuk letupan yang terjadi di Bleduk Kuwu dan besar intensitas frekuensi letupannya dapat menjadi studi awal untuk penelitianpenelitian selanjutnya.

Metode yang akan digunakan dalam penelitian ini adalah dengan perekaman data seimik dan perekaman data visual. Data seismik digunakan untuk mencari besar frekuensi dan data visual digunakan untuk memperoleh macam-macam letupan dan diameter letupan.

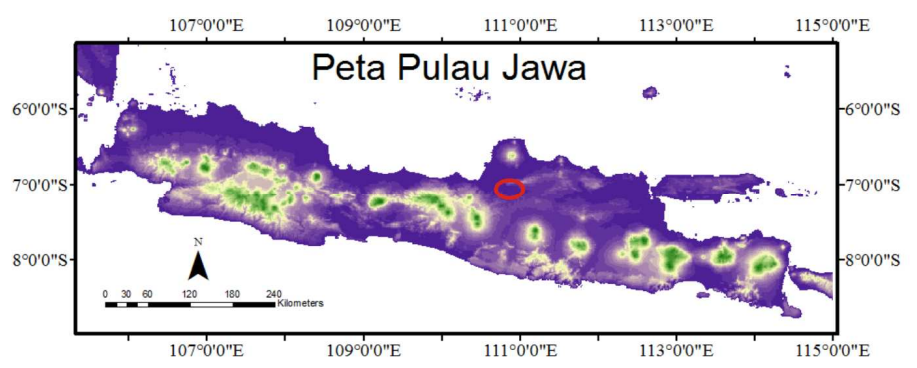

a)

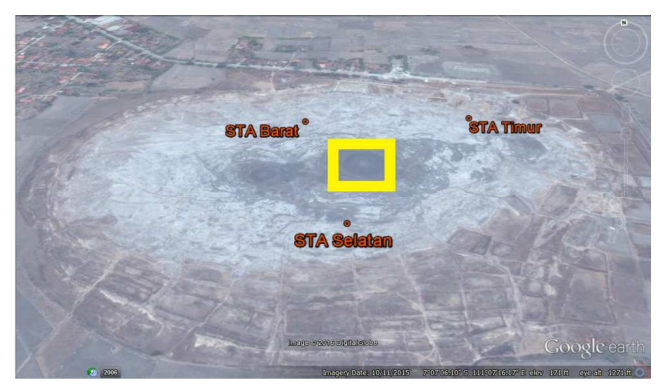

b)

Gambar 1. Peta lokasi gunung lumpur Bleduk Kuwu

a) Pulau Jawa, tanda merah menunjukkan letak gunung lumpur Bleduk Kuwu

b) Gunung lumpur Bleduk Kuwu dengan tiga stasiun titik amat (STA) penelitian menggunakan citra satelit Google Earth. Tanda kuning menunjukkan sumber letupan

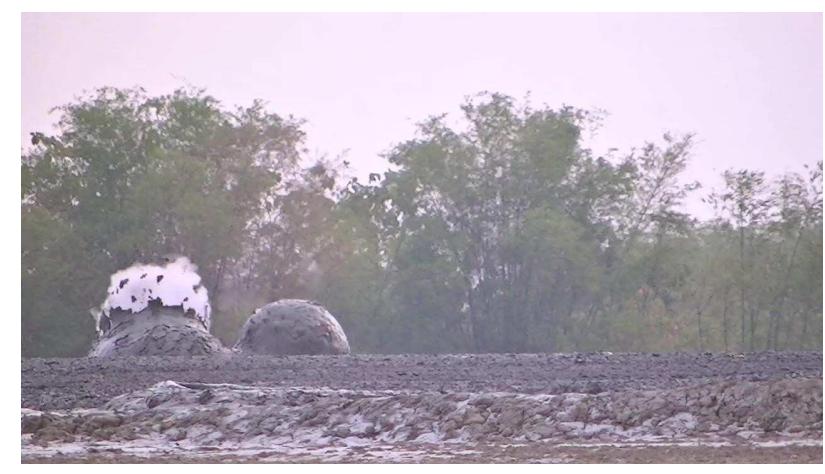

Gambar 2. Penampakan Letupan Bleduk Kuwu 


\section{Tinjauan Pustaka}

\section{Gunung Api Lumpur}

Menurut Sugianto (2015) definisi dari gunung lumpur adalah fenomena intrusi dan ekstrusi material lempung yang berasal dari dalam Bumi. Material tersebut terdorong ke atas melewati celah yang disebabkan karena rekahan atau patahan. Celah tersebut kemudian menjadi jalur aliran lumpur vulkanik yang menimbulkan susunan litologi berupa sedimen material lempung di permukaan.

Konsep sederhana dari gunung lumpur dapat diasumsikan sama seperti gunungapi. Model gunung lumpur Bleduk Kuwu seperti ditunjukkan pada Gambar 3. Disebutkan oleh Zoporowski (2009) konsep model dari gunung lumpur dapat diasumsikan terdiri dari mud reservoir (kantong lumpur atau tempat penyimpanan lumpur) dan conduit (pipa lumpur). Conduit berfungsi sebagai jalan keluar material dari dalam bumi ke permukaan. Mud reservoir berfungsi sebagai tempat terakumulasinya material yang akan dikeluarkan ke permukaan. Mud reservoir terdapat di bawah permukaan dengan kedalaman tertentu. Di permukaan, pipa lumpur membentuk sebuah kawah utama atau main crater (Dimitrov, 2002). Selain kawah utama, biasanya juga terdapat satellite crater atau secondary crater yang merupakan hasil dari penerobosan terhadap jalur pipa lumpur. Pipa lumpur atau conduit, biasanya juga disebut sebagai feeder channel.

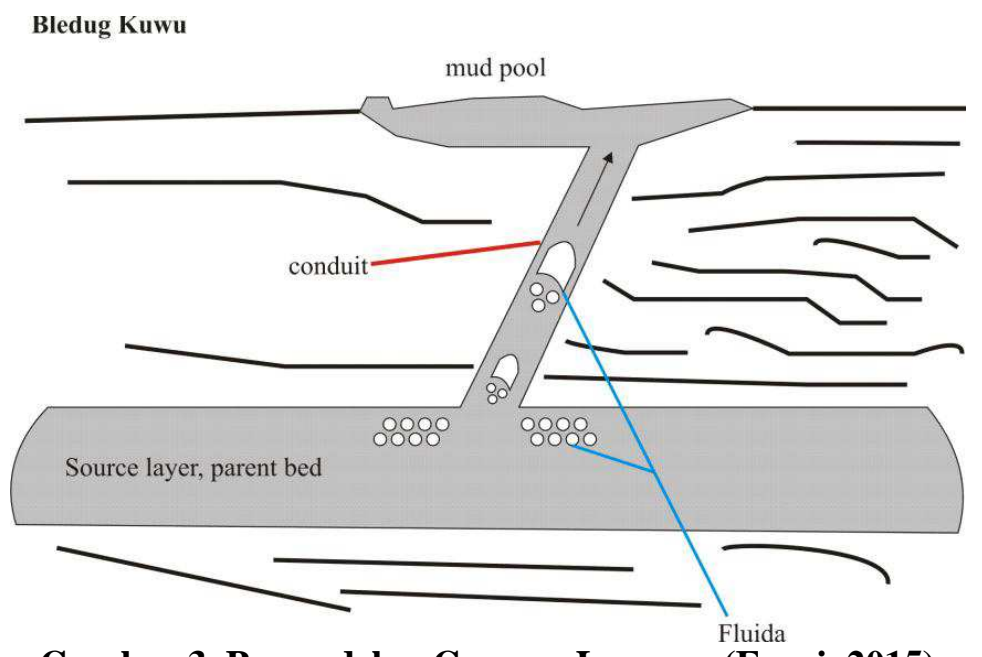

Gambar 3. Permodelan Gunung Lumpur (Fauzi, 2015)

\section{Bleduk Kuwu}

Daerah Purwodadi menurut Bammelen (1949) termasuk ke dalam zona Randublatung. Kenampakan fisiografi adalah zona depresi yang memisahkan antara zona Kendeng bagian selatan dan zona Rembang bagian utara. Daerah Purwodadi juga termasuk endapan alluvial.

Indriana (2007) melakukan penelitian dengan tujuan menginterpretasikan objek anomali bawah permukaan. Disebutkan bahwa anomali di daerah Bleduk Kuwu berasal dari batuan yang mengalami patahan. Patahan tersebut memanjang dari arah Barat Daya menuju ke arah Timur Laut. Patahan ini akan mengakibatkan keluarnya aliran gas ke permukaan Bumi.

Pengamatan dari pemodelan kecepatan di bawah permukaan Bleduk Kuwu oleh Putranti (2015), disebutkan bahwa terdapat dua lapisan batuan bawah permukaan Bleduk Kuwu. Lapisan pertama dengan $\mathrm{v}_{\mathrm{p}}$ dan $\mathrm{v}_{\mathrm{s}}$ sekitar $1600 \mathrm{~m} / \mathrm{s}$ dan $300 \mathrm{~m} / \mathrm{s}$ dengan kedalaman sekitar 80 meter. Serta lapisan kedua dengan $\mathrm{v}_{\mathrm{p}}$ dan $\mathrm{v}_{\mathrm{s}}$ sekitar $2800 \mathrm{~m} / \mathrm{s}$ dan $500 \mathrm{~m} / \mathrm{s}$ dengan kedalaman lebih dari 80 meter.

Penelitian yang dilakukan oleh Rugayya (2015) dengan menganalisis sinyal referensi dan sinyal event secara kuantitatif menggunakan kriteria Time-Frequency misfit dan goodness- 
of-fit diperoleh 4 tipe sinyal referensi semburan lumpur Bleduk Kuwu. Tipe sinyal tersebut antara lain tipe A yang menyemburkan satu gelembung letupan, tipe B menyemburkan dua gelembung letupan pada waktu yang sama, tipe $\mathrm{C}$ menyemburkan lebih dari dua gelembung letupan, dan tipe D menyemburkan gelembung letupan yang besar.

\section{Transformasi Fourier}

Transformasi fourier digunakan untuk mengubah sinyal seismik dari kawasan waktu menjadi kawasan frekuensi. Data yang diperoleh adalah dalam kawasan waktu, sehingga untuk melihat frekuensi yang terkandung di dalam data tersebut digunakan transformasi Fourier. Persamaan transformasi Fourier ditunjukkan seperti (Brigham, 1988) :

$$
H(f)=\int_{-\infty}^{\infty} h(t) e^{-j 2 \pi t t} d t
$$

$\mathrm{h}(\mathrm{t})$ adalah tanggapan impuls yang merupakan fungsi dari kawasan waktu. $\mathrm{H}(\mathrm{f})$ hasil transformasi fourier dari $\mathrm{h}(\mathrm{t})$ yang merupakan fungsi dari kawasan frekuensi.

\section{Penapisan Frekuensi}

Penapisan frekuensi adalah suatu perangkat untuk menghilangkan atau mengurangi gangguan sinyal yang tidak diinginkan atau menyertai suatu sinyal utama atau sinyal yang diharapkan (waluyo, 2011). Penapisan frekuensi diperlukan untuk memperoleh frekuensi dari event letusan Bleduk Kuwu dan menghilangkan frekuensi yang diakibatkan dari aktivitas (noise) yang terjadi di sekitar tempat perekaman. Terdapat beberapa macam penapisan frekuensi, salah satunya adalah Bandpass filter. Bandpass filter adalah untuk menghilangkan frekuensi yang kurang atau melebihi dari batas frekuensi yang telah ditentukan.

\section{Kamera Perekam}

Kamera perekam yang digunakan untuk penelitian adalah JVC Everio GZ-HM30AG. Dimensi kamera 50,5 mm x $55 \mathrm{~mm}$ x 110,5 mm (Victor company of Japan, 2010). Sebelum melakukan pengambilan data lapangan, hal yang perlu dilakukan adalah memastikan letupan Bleduk Kuwu dapat terlihat jelas pada kamera perekam. Kalibrasi perekaman yang dilakukan pada penelitian ini untuk mencari ukuran letupan yang sebenarnya, dengan cara membuat media ukur.

\section{Metodologi Penelitian}

Tempat penelitian berada di Gunung Lumpur Bleduk Kuwu, Desa Kuwu, Kecamatan Kradenan, Kabupaten Grobogan, Jawa Tengah. Waktu pengambilan data dilakukan pada tanggal 30 September 2013 selama 47 menit 27 detik. Pengambilan data penelitian dilakukan di tiga titik lokasi (STA Barat, STA Timur, dan STA Selatan). Jarak antara masing-masing titik stasiun dengan sumber letupan tidak sama, seperti terlihat pada Gambar 1b. Posisi dari masing-masing titik stasiun ditunjukkan pada Tabel 1.

Tabel 1. Posisi dari Tiga Stasiun Titik Amat

\begin{tabular}{|c|c|c|c|}
\hline $\begin{array}{c}\text { Stasiun Titik } \\
\text { Amat }\end{array}$ & $\begin{array}{c}\text { Jarak Stasiun Titik Amat } \\
\text { Dengan Sumber Letupan (m) }\end{array}$ & $\begin{array}{c}\text { Elevasi } \\
(\mathbf{m})\end{array}$ & Koordinat \\
\hline STA Barat & 110,74 & 54 & $7^{\circ} 7^{\prime} 0,876 \mathrm{LS}$ dan $111^{\circ} 7^{\prime} 15,546 \mathrm{BT}$ \\
\hline STA Selatan & 135,91 & 56 & $7^{\circ} 7^{\prime} 7,788 \mathrm{LS}$ dan $111^{\circ} 7^{\prime} 16,47 \mathrm{BT}$ \\
\hline STA Timur & 149,31 & 60 & $7^{\circ} 7^{\prime} 1,266 \mathrm{LS}$ dan $111^{\circ} 7^{\prime} 22,254 \mathrm{BT}$ \\
\hline
\end{tabular}

Alat penelitian yang digunakan terdapat dua macam, yaitu alat untuk mengambil data seismik dan data visual. Kedua alat ini dijalankan dalam waktu yang bersamaan. Untuk mengambil data seismik digunakan 3 set unit TDV-23S feedback short period seismometer 
yang dilengkapi dengan digitizer, kabel konektor, kabel lan, panel surya, laptop, antena gps, dan kompas. Selain itu, digunakan juga GPS portable, alas sensor, aki, tenda, meteran, jam tangan, ember, dan alat penggali tanah. Sedangkan pengambilan data visual menggunakan handycam JVC Everio yang dipasangkan pada tripod. Pemasangan alat di lapangan seperti ditunjukkan pada Gambar 4.

Tahap pengambilan data dilakukan dengan dua metode perekaman, merekan data seismik dan visual. Kedua perekaman tersebut dilakukan secara bersamaan. Pada perekaman data seismik di masing-masing stasiun titik amat, seismometer diletakkan pada sebuah lubang berukuran $60 \mathrm{~cm}$ x $60 \mathrm{~cm}$ dengan kedalaman $(40-60) \mathrm{cm}$. Di bagian bawah lubang diberikan alas dari beton dengan tebal sekitar $\pm 6 \mathrm{~cm}$. Seismometer diletakkan di atas alas kemudian ditutup dengan ember untuk mengurangi noise yang diakibatkan oleh gangguan angin. Perekaman data visual dilakukan dengan memasangkan kamera pada tripod agar posisi stabil dan tidak bergeser. Kamera perekam tersebut kemudian diletakkan di samping seismometer. Tinggi kamera yang dipasangkan pada tripod adalah $80 \mathrm{~cm}$.

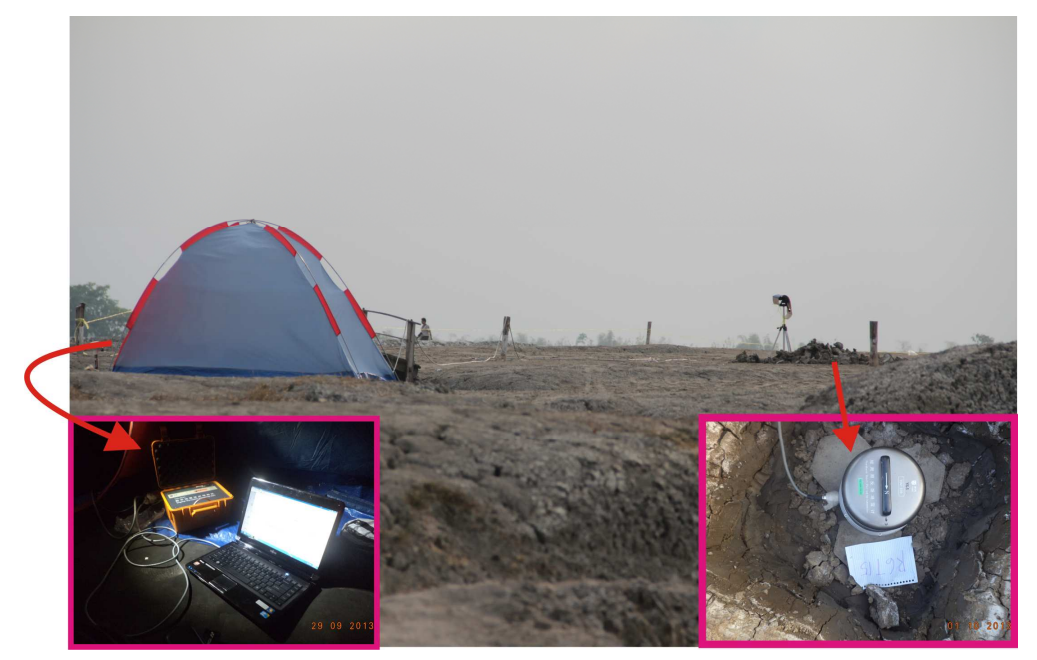

\section{Gambar 4. Pemasangan alat di STA Timur saat Pengambilan Data Lapangan Seismometer dan Kamera Perekam diletakkan Secara Berdampingan}

Tahap pengolahan data dilakukan yaitu menganalisis data seismik dan visual. analisis data seismik yaitu menganalisis besar frekuensi letupannya, dengan menggunakan program Obspy dan Geopsy. Sedangkan analisis visual dengan cara menginventarisasi bentuk letupan. Video rekaman letupan bleduk Kuwu dianalisis dengan menggunakan program everio media browse. Video letupan di potong menjadi photo saat terjadi letupan dengan ukuran paling besar dan masih berbentuk setengah ellipsoid. Gambar hasil pemotongan di ukur panjang diameter dan tingginya dengan menggunakan media ukur yang telah dibuat.

Media ukur dibuat untuk memperoleh ukuran gambar yang sebenarnya. Pada saat pengambilan data di lapangan untuk memperoleh ukuran besar diameter dan tinggi letupan Bleduk Kuwu secara langsung sangat sulit, karena objek penelitian berada pada kolam lumpur yang luas. Untuk membuat media ukur digunakan tongkat dengan panjang 2 meter dan mempunyai skala $20 \mathrm{~cm}$. Tahap pembuatan media ukur yaitu 1) merangkai alat seperti pada saat pengambilan data, 2) merekam tongkat berskala, 3) memotong rekaman tongkat berskala menjadi photo, 4) dengan Corel Draw, membuat garis yang panjangnya sesuai dengan photo tersebut, 5) garis tersebut kemudian dibuat skala 10 bagian yang masingmasing mewakili panjang $20 \mathrm{~cm}$ pada ukuran tongkat yang sebenarnya. Desain pembuatan media ukur seperti pada Gambar 5. Pembuatan media ukur dilakukan di Kampus FTMIPA UGM. 


\section{Media Ukur}

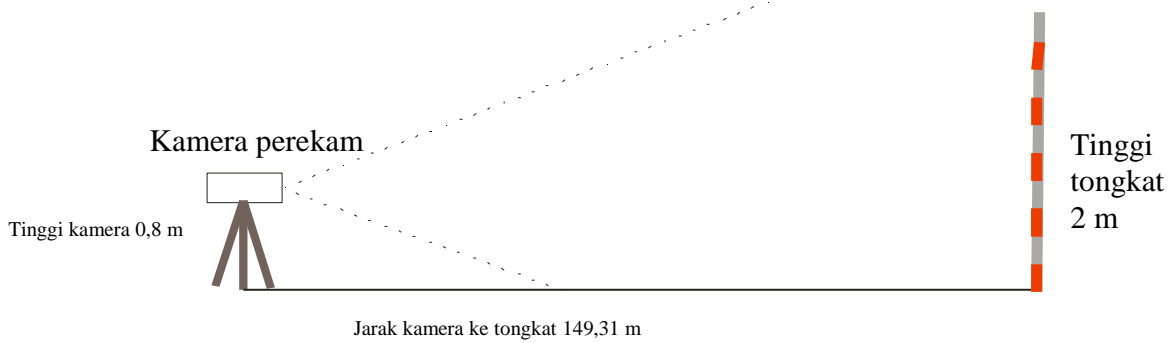

\section{Gambar 5. Desain Pembuatan Media Ukur. Ukuran Pemasangan Alat disesuaikan dengan Ukuran Pada Saat Pengambilan Data di lapangan}

Tahapan pengukuran panjang diameter dan tinggi letusan yaitu dengan memotong video rekaman letupan Bleduk Kuwu saat posisi terbesar dan masih berbentuk ellipsoid. Kemudian, hasil potongan diukur dengan menggunakan media ukur yang telah dibuat.

\section{Hasil dan Pembahasan}

\section{a. Frekuensi letupan Bleduk Kuwu}

Hasil perekaman sinyal seismik dari STA Barat, STA Timur, dan STA Selatan, data yang dianalisis hanyalah komponen vertikal (z). Waktu dari data seismik untuk masing-masing analisis spektogram adalah tiga menit. Salah satu hasil dari analisis spektogram speerti pada Gambar 6. Kandungan frekuensi letupan Bleduk Kuwu berada di bawah $2 \mathrm{~Hz}$ sampai dengan $4 \mathrm{~Hz}$.

Analisis selanjutnya dengan menggunakan time frequency analisis (TFA) pada program geopsy. Hasil analisis menggunakan TFA diperoleh bahwa frekuensi letupan berada pada $(1,64-4,19) \mathrm{Hz}$.

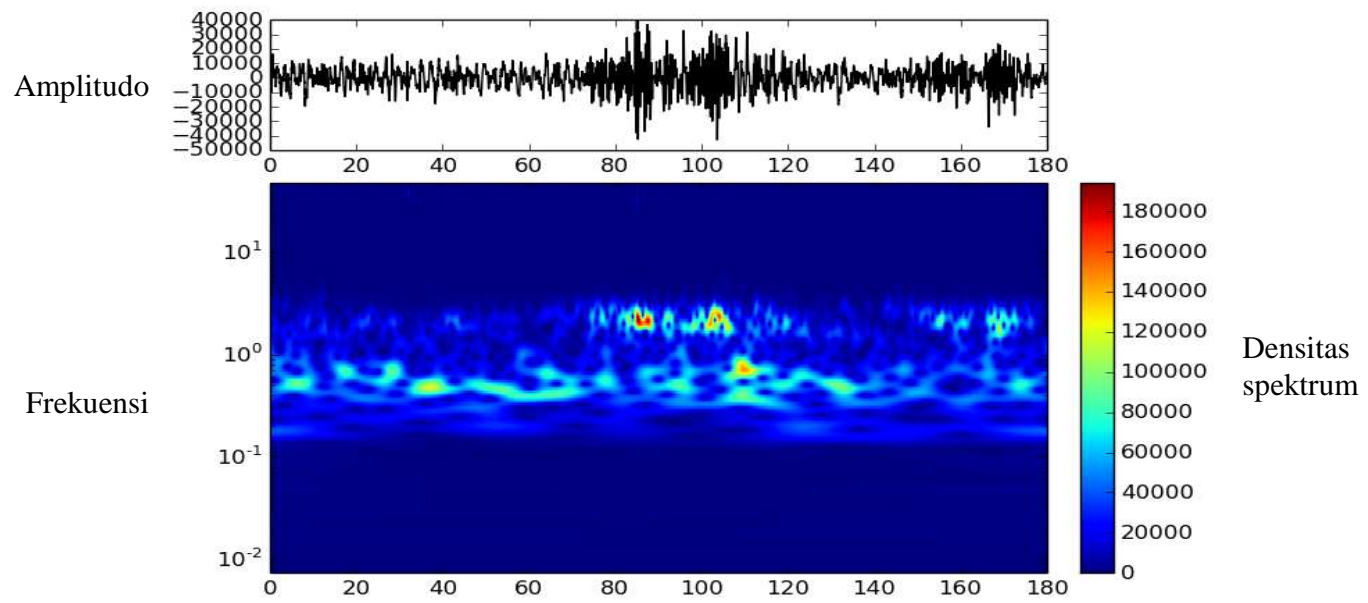

\section{Gambar 6. Analisis Frekuensi di Stasiun Barat pada Waktu 15.06.00 WIB - 15.09.00 WIB.}

Data seismik kemudian ditapis dengan menggunakan bandpass filter. Penapisan dilakukan dengan batas nilai frekuensi $1,64 \mathrm{~Hz}-4,19 \mathrm{~Hz}$. Data tersebut kemudian dianalisis kembali 
dengan menggunakan analisis spektrum untuk mencari frekuensi dominannya. Hasil analisis spektrum diperoleh frekuensi dominan berada di sekitar $2 \mathrm{~Hz}$.

a)

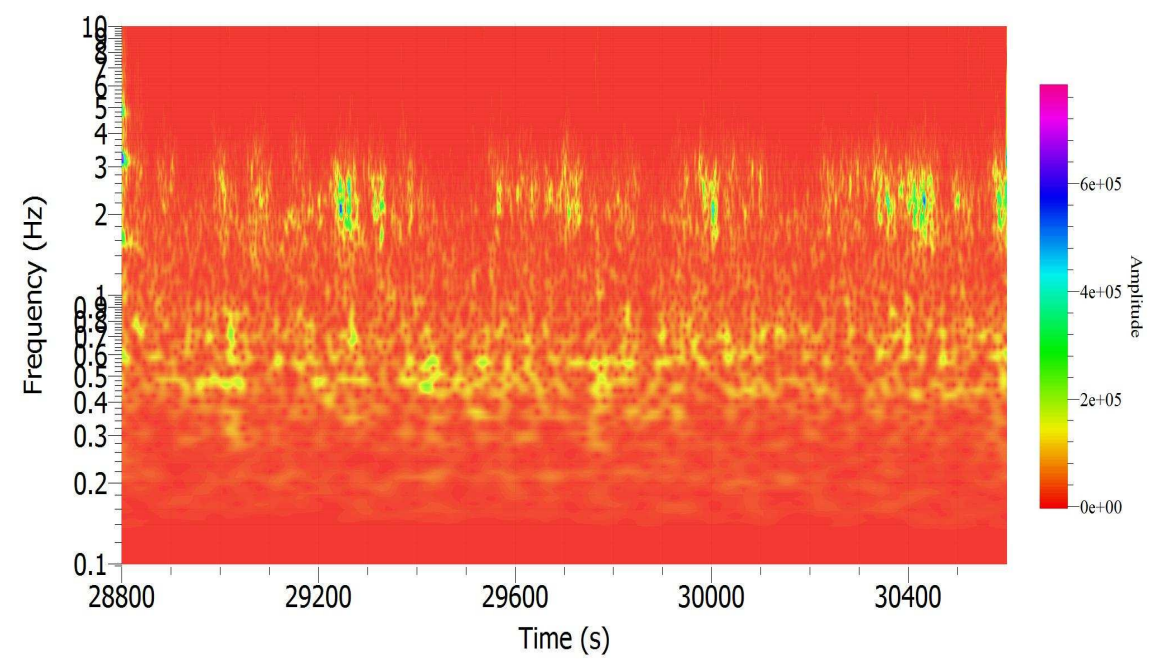

b)

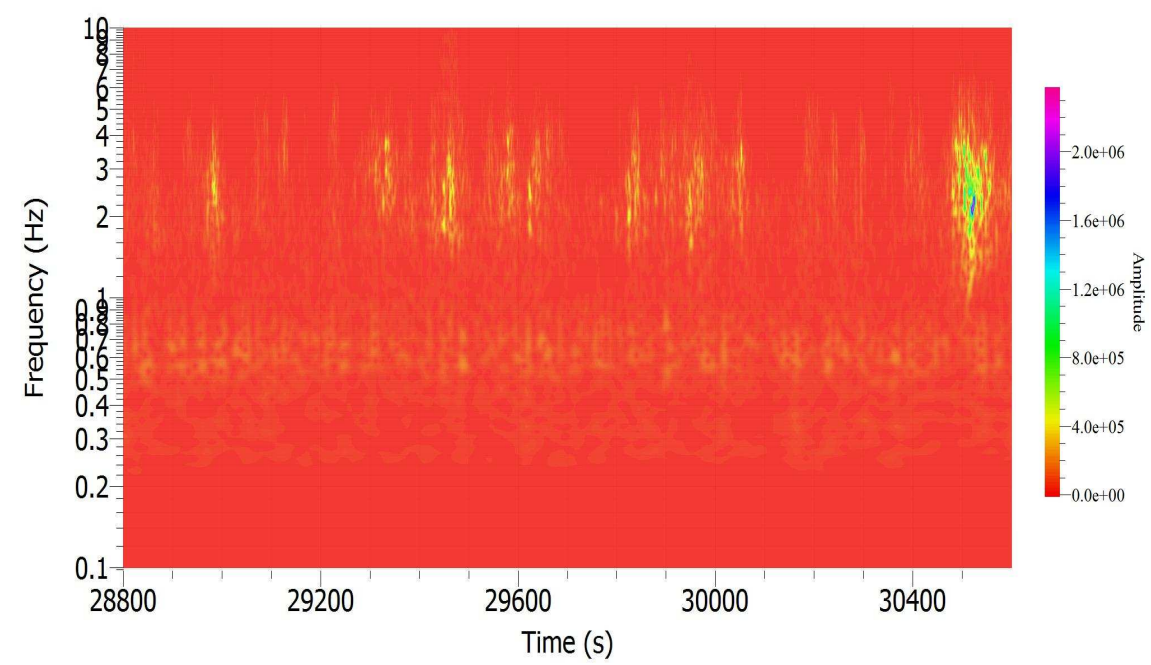

c)

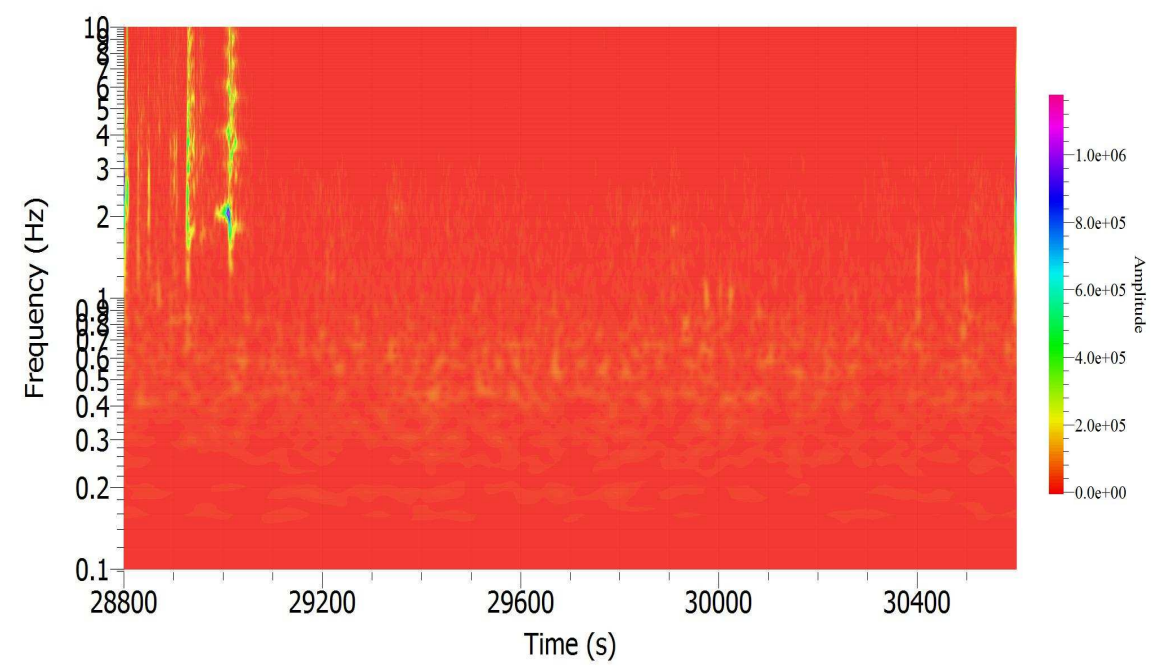

Gambar 7. Analisis Frekuensi Menggunakan Time Frequency Analisys (TFA) Diperoleh Frekuensi $(1,6$ - 4,2) Hz. 
Data yang dianalisis adalah data pada komponen vertikal (z) dari tiga stasiun a) STA Barat, b) STA Timur, dan c) STA Selatan. Data yang dianalisis adalah pukul 15.00.00 WIB 15.30.00 WIB.

\section{b. Macam-macam Bentuk Letusan Bleduk Kuwu}

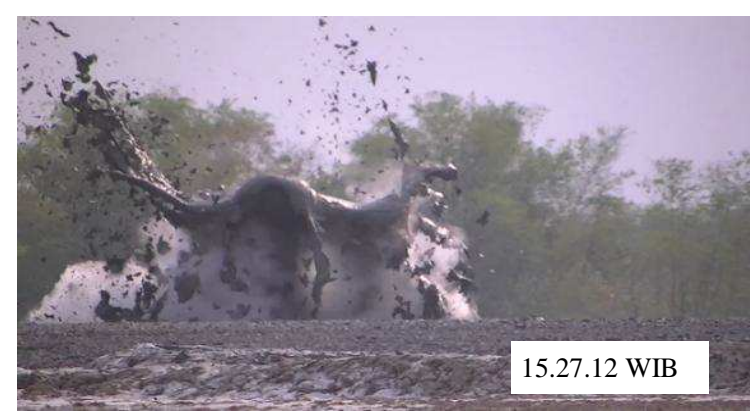

a)

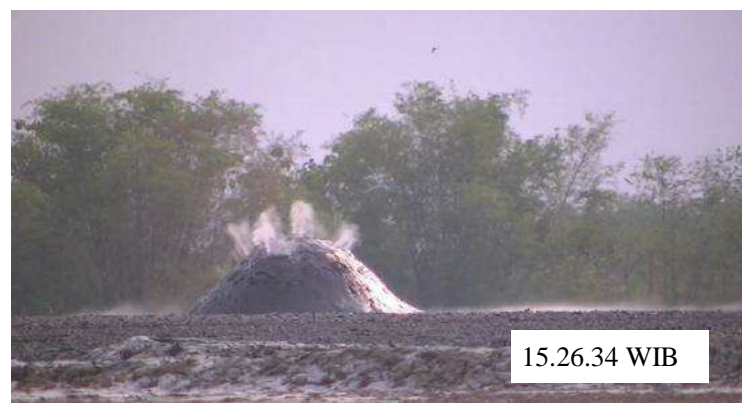

c)

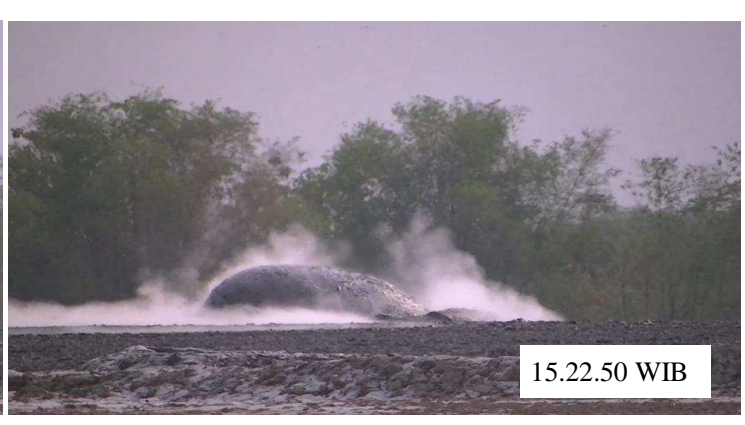

b)

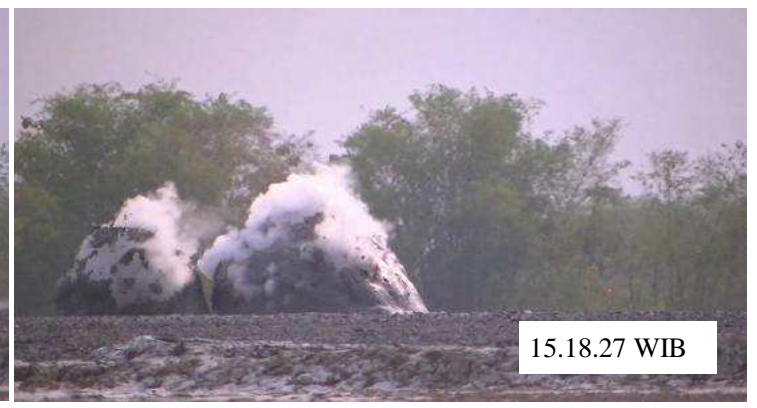

d)

Gambar 8. Letupan yang terjadi di Bleduk Kuwu saat pengambilan data

Waktu letupan ditunjukkan di kanan bawah pada gambar. a) letupan kuat, b) letupan beruntun, c) letupan biasa, d) letupan ganda.

Hasil analisis visual diperoleh empat bentuk letupan yang sering terjadi di Bleduk Kuwu. Gambar ke-empat macam letupan ditunjukkan pada Gambar 8. Adapun bentuk tersebut antara lain :

1) Letupan kuat

Karakteristik dari letusan kuat yaitu bentuk letusan cenderung tidak terduga dan tidak beraturan. Bentuk letusan yang tidak beraturan menyebabkan tinggi dan diameter letusan sulit untuk diukur. Tetapi, meski sulit untuk diukur secara kasat mata terlihat mempunyai ukuran besar dan ada juga yang berukuran tidak terlalu besar. Selama waktu penelitian terjadi sekitar 8 kali letusan. Bentuk letusan kuat seperti pada Gambar 8 (poin a) .

2) Letupan beruntun

Letupan beruntun merupan letupan yang terjadi secara beruntun dan terdiri dari dua atau lebih letupan. Umumnya, tinggi dari letupan beruntun ini tidaklah terlalu tinggi. Tetapi dapat mempunyai diameter yang lumayan panjang. Selama waktu perekaman, terdapat sekitar 17 kali letupan. Bentuk letusan kuat seperti pada Gambar 8 (poin b).

3) Letupan ganda

Letupan ganda adalah letupan yang terdiri dari dua atau lebih letupan dalam waktu yang sama atau hampir sama. letupan tersebut saling berhubungan antara satu dengan yang lainnya, atau beberapa sentimeter atau meter antar letupan. Dimensi dari letupan ganda bervariasi, ada yang besar semua, besar dan kecil, maupun kecil 
semua. Selama perekaman, terjadi sekitar 34 kali letupan ganda. Bentuk letusan kuat seperti pada Gambar 8 (poin d) .

4) Letupan Biasa

Letupan Biasa sering terjadi di Bleduk Kuwu. Letupan ini umumnya merupakan letupan single dan tidak mempunyai ciri kusus seperti pada letupan poin 1,2, dan 3 . Dimensi letupan bervariasi, dari ukuran kecil sampai dengan besar. Bentuk letusan kuat seperti pada Gambar 7 (poin c).

Letupan yang terjadi diukur besar diameternya dan diperoleh panjang diameter maksimal selama pengambilan data adalah $(3,06 \pm 0,10) \mathrm{m}$. Panjang diameter maksimal ini digunakan untuk mengklasifikasikan besar diameter letusan dalam 3 kelompok, yaitu kelompok besar (diameter letupan $>2 \mathrm{~m}$ ), kelompok medium $(1 \mathrm{~m}-2 \mathrm{~m}$ ), dan kelompok kecil (diameter letupan < 1 meter). Diperoleh letupan dengan diameter besar berjumlah 91 letupan, diameter medium berjumlah 374 letupan, dan diameter kecil 37 letupan. Selama pengukuran diameter letupan, terdapat diameter letupan yang sulit diukur. Hal ini disebabkan karena letusan yang tertutup asap, letusan terdapat rongga, dan bentuk dari letusan yang tidak beraturan sehingga menyebabkan kesulitan menentukan panjang diameternya. Banyaknya letupan yang sulit terukur panjang diameternya berjumlah sekitar 39 letusan.

\section{c. Pembahasan}

Selama pengambilan data di Bleduk Kuwu (47 menit 26 detik), terdapat sekitar \pm 541 letupan. Letupan-letupan tersebut tidak hanya bervariasi dari hal diameternya, tetapi juga dalam hal bentuk letupannya. Pengambilan data letupan dengan cara merekam letupan menggunakan kamera perekam. Dari sekian banyaknya letupan yang terekam selama pengambilan data, diperoleh 4 macam kelompok bentuk letupan yang sering terjadi. Dimana pengelompokan tersebut didasarkan pada karakteristik letupan yang sama atau hampir sama. Empat kelompok tersebut antara lain letupan kuat, letupan beruntun, letupan ganda, dan letupan biasa. Hasil dari pengelompokan letupan ini, sesuai dengan empat tipe sinyal referensi semburan lumpur Bleduk Kuwu oleh Rugayya (2015). Rugaya menjelaskan tipetipe tersebut ke dalam tipe $\mathrm{A}$, tipe $\mathrm{B}$, tipe $\mathrm{C}$, dan tipe $\mathrm{D}$. Tipe $\mathrm{A}$ menyemburkan satu gelembung letupan. Tipe B menyemburkan menyemburkan dua gelembung letupan. Tipe $\mathrm{C}$ menyemburkan lebih dari dua gelembung letupan dan tipe D menyemburkan gelembung letupan yang besar.

Kemudian, data rekaman letupan kemudian dianalisis dengan dengan cara memotong tiaptiap letupan dan mengubahnya menjadi sebuah photo agar dapat di cari panjang diameternya. Media ukur dibuat untuk mencari diameter masing-masing letupan. Analisis pengukuran diameter diperoleh bahwa diameter maksimal yang terukur sekitar $(3,06 \pm 0,10) \mathrm{m}$, dengan diameter letupan yang sering terjadi sekitar $(1,00-2,00) \mathrm{m}$.

Data seismik dianalisis untuk mencari besar nilai frekuensi letupan. Analisis frekuensi dilakukan dengan menggunakan analisis spektrogram pada program obspy dan TFA pada program Geopsy (Gambar 6 dan Gambar 7). Hasil dari analisis frekuensi diperoleh 1,6 Hz $4,2 \mathrm{~Hz}$ dan diperoleh frekuensi dominan berada pada $2 \mathrm{~Hz}$. Asumsi awal nilai ini merupakan frekuensi dari letupan Bleduk Kuwu di permukaan. Tetapi, perlu dilakukan pencocokan terhadap waktu tiba gelombang seismik dengan waktu letupannya. Penelitian tentang frekuensi letupan juga pernah dilakukan oleh Sugiantoro (1989) menyebutkan bahwa besar frekuensi letupan gelembung yang merupakan akibat dari pengaruh kakas apung bervariasi antara $0,60 \mathrm{~Hz}-0,90 \mathrm{~Hz}$. Selain itu, juga diperoleh frekuensi antara $1,25 \mathrm{~Hz}$ sampai 2,40 $\mathrm{Hz}$ yang merupakan frekuensi letusan gelembung. Nilai frekuensi letusan gelembung tersebut tidak jauh berbeda dengan hasil nilai frekuensi yang diperoleh oleh peneliti. 


\section{Simpulan dan Saran}

Kesimpulan dari analisis data, diketahui bahwa terdapat empat macam jenis letupan yang terdapat di Bleduk Kuwu. letupan-letupan tersebut antara lain letupan kuat, letupan beruntun, letupan ganda, dan letupan biasa. Masing-masing dari letupan tersebut mempunyai ciri atau karakteristik yang berbeda antara satu dengan yang lainnya. Kemudian, dari masing-masing letupan di analisis besar diameternya. Hasil dari analisis menyatakan ukuran terbesar dari diameter yang terukur yaitu $(3,06 \pm 0,10)$ meter, dengan panjang diameter paling banyak terjadi yaitu $(1,00-2,00)$ meter. Apabila untuk masing-masing letupan dicari besar tingginya, maka dapat dicari besar volume untuk tiap-tiap letupan yang terjadi. Sehingga dapat diketahui volume muntahan material lumpur Bleduk Kuwu selama pengukuran.

Besar frekuensi letupan di Bleduk Kuwu diperoleh $(1,6$ - 4,2) $\mathrm{Hz}$, dengan frekuensi dominannya $2 \mathrm{~Hz}$. Asumsi bahwa nilai frekuensi ini merupakan nilai letupan di permukaan, perlu dilakukan pencocokan antara waktu letusan dan waktu rekaman data seismiknya.

\section{Daftar Pustaka}

Bammelen, R. W. V. (1949). The Geology of Indonesia Vol. 1A. The Huge : Government Printing Office.

Brigham, E., O. (1988). The Fast Fourier Transform and Its Applications. New Jersey : Prentice Hall.

Dimitrov, L. I. (2002). Mud Volcanoes - The most Important Pathway for Degassing Deeply Buried Sediments. Earth-Science Rev. 59, page 49-76.

Fauzi P., A. (2015). Pembuatan Model Fisis Letusan Gunung Lumpur Bledug Kuwu dan Pemodelan Numerik untuk Mengetahui Kecepatan Perambatan Gelombang Seismiknya. Thesis. Fakultas Matematika dan Ilmu Pengetahuan Alam. Universitas Gadjah Mada.

Gela M Saka, Bergita. (2015). Pemodelan Bawah Permukaan Gunung Lumpur Bledug Kuwu, Grobogan, Jawa Tengah Berdasarkan Inversi Data Mikrotremor. Thesis. Fakultas Matematika dan Ilmu Pengetahuan Alam. Universitas Gadjah Mada.

Indriana, R. D., Nurwidyanti, M. I., Haryono, K.W.(2007). Interpretasi Bawah Permukaan dengan Metode Self Potential Daerah Bleduk Kuwu Kradenan Grobogan. Berkala Fisika, No. 3, Vol. 10, Hal 155-167.

Istadi, B. P. (2009). Modeling Study of growth and potential geohazard for LUSI mud Volcano: East Java, Indonesia. Marine and Petroleum Geology 26 (1724 - 1739).

Putranti, A.B. (2015). Pemodelan Kecepatan Medium Bawah Permukaan Bledug Kuwu Dengan Metode Spatial Autocorrelation (SPAC). Thesis. Fakultas Matematika dan Ilmu Pengetahuan Alam. Universitas Gadjah Mada.

Rugayya, S. (2015). Karakterisasi Sinyal Seismik di Bledug Kuwu, Grobogan, Jawa Tengah Menggunakan Kriteria Time-Frequency Misfit dan Goodness-Of-Fit. Thesis. Fakultas Matematika dan Ilmu Pengetahuan Alam. Universitas Gadjah Mada.

Sugianto, N.(2014). Analisis Polarisasi Gelombang Seismik Erupsi Bledug Kuwu Menggunakan Seismometer 3 Komponen. Thesis. Fakultas Matematika dan Ilmu Pengetahuan Alam. Universitas Gadjah Mada.

Sugiantoro. (1989). Studi Gelombang Seismik Mikro Pada Medium Dua Fase di Daerah Kuwu Kabupaten Grobogan Jawa Tengah. Skripsi. Fakultas Matematika dan Ilmu pengetahuan Alam. Universitas Gadjah Mada Yogyakarta.

Victor Company of Japan. (2010). Camcorder GZ-HM30AG Basic User Guide.

Waluyo. (2011). Diktat Kuliah Analisis Runtun Waktu. Program Studi Geofisika. Universitas Gadjah Mada.

Zoporowski, A., Miller, S. A. (2009). Modelling Eruption Cycles And Decay of Mud Volcanoes. Marine and Petroleum Geology, page 1879- 1887. 